\title{
Os impactos e desafios da COVID-19 nas favelas e a questão da (in)visibilidade
}

\author{
The impacts and challenges of COVID-19 in the favelas and the issue of (in)visibility \\ Los impactos y desafíos del COVID-19 en las favelas y el tema de la (in)visibilidad
}

Recebido: 05/01/2022 | Revisado: 10/01/2022 | Aceito: 12/01/2022 | Publicado: 14/01/2022

Vinicius de Lima Lovadini

ORCID: https://orcid.org/0000-0001-9066-2160

Universidade de São Paulo, Brasil

E-mail: viniciuslovadini@usp.br

Cristine Maria Pereira Gusmão

ORCID: https://orcid.org/0000-0002-6019-8325

Centro Universitário Tiradentes, Brasil E-mail: cryspempg@gmail.com

Rodrigo Mota de Oliveira ORCID: https://orcid.org/0000-0002-5628-0131

Universidade de São Paulo, Brasil E-mail: rodrigoo@usp.br

Daiane Gabiatt

ORCID: https://orcid.org/0000-0002-0878-7149

Universidade de São Paulo, Brasil

E-mail: daia-gabiatti@hotmail.com

Jefferson Militão da Silva

ORCID: https://orcid.org/0000-0002-1198-4813 Centro Universitário de Rio Preto, Brasil

E-mail: jeffersonsilva.fisio@gmail.com

Anelieze Marques de Souza

ORCID: https://orcid.org/0000-0001-8924-7787 Universidade Paulista, Brasil

E-mail: souzaanelieze@gmail.com

Cláudia Cardoso de Oliveira

ORCID: https://orcid.org/0000-0001-8875-7902

Universidade de São Paulo, Brasil

E-mail: claudiacardosoo@usp.br

Renata Karina Reis

ORCID: https://orcid.org/0000-0002-0681-4721

Universidade de São Paulo, Brasil

E-mail: rkreis@eerp.usp.br

Mayra Gonçalves Menegueti

ORCID: https://orcid.org/0000-0001-7955-4484

Universidade de São Paulo, Brasil

E-mail: mayramenegueti@usp.br

Elucir Gir

ORCID: https://orcid.org/0000-0002-3757-4900

Universidade de São Paulo, Brasil

E-mail: egir@eerp.usp.br

\begin{abstract}
Resumo
Objetivo: Identificar na literatura evidências acerca dos impactos e desafios que a COVID-19 têm causado nas favelas. Métodos: Revisão integrativa de literatura, na qual buscou-se publicações do ano de 2020 no Portal de Periódicos CAPES/MEC, no SciELO e Pubmed com os descritores e suas combinações nos idiomas português e inglês: "Favelas" and "Covid-19". Resultados: Os autores apontam impactos em diversas áreas na vida da população que vive em favelas, que vão desde maiores riscos de contaminação devido a aglomeração e os prejuízos à saúde, o estado nutricional, uma vez que essa população tem suas fontes de renda prejudicadas e questões de cunho social, como ocorreu com as crianças que ficaram sem ir à escola e merendar. Conclusão: São grandes os desafios para o enfrentamento da COVID-19 dentre eles os marcadores sociais da diferença, as dificuldades no acesso aos meios de saúde e a escassez de renda para as despesas básicas.
\end{abstract}

Palavras-chave: Infecções por coronavírus; Áreas de pobreza; Vulnerabilidade e desastres.

\section{Abstract}

Objective: To identify evidence in the literature about the impacts and challenges that COVID-19 has caused in favelas. Methods: Integrative literature review, which sought publications from the year 2020 in the CAPES/MEC Journal Portal, in SciELO and Pubmed with the descriptors and their combinations in Portuguese and English: 
"Favelas" and "Covid-19". Results: The authors point out impacts in several areas in the lives of the population living in slums, ranging from greater risks of contamination due to overcrowding and damage to health, nutritional status, as this population has its sources of income impaired and issues of a social nature, as occurred with the children who did not go to school and have lunch. Conclusion: The challenges facing COVID-19 are great, among them the social markers of difference, the difficulties in accessing health care and the lack of income for basic expenses.

Keywords: Coronavirus infections; Poverty areas; Disaster vulnerability.

\section{Resumen}

Objetivo: Identificar evidencia en la literatura sobre los impactos y desafíos que COVID-19 ha causado en las favelas. Métodos: Revisión integrativa de la literatura, que buscó publicaciones del año 2020 en el Portal de Revistas CAPES / MEC, en SciELO y Pubmed con los descriptores y sus combinaciones en portugués e inglés: "Favelas" y "Covid-19". Resultados: Los autores señalan impactos en varias áreas en la vida de la población que vive en tugurios, que van desde mayores riesgos de contaminación por hacinamiento y daños a la salud, estado nutricional, ya que esta población tiene sus fuentes de ingresos deterioradas y problemas de carácter social, como ocurrió con los niños que no iban a la escuela ni almorzaban. Conclusión: Los desafíos que enfrenta el COVID-19 son grandes, entre ellos los marcadores sociales de diferencia, las dificultades para acceder a la atención médica y la falta de ingresos para los gastos básicos.

Palabras clave: Infecciones por Coronavirus; Áreas de pobreza; Vulnerabilidad ante desastres.

\section{Introdução}

A doença pelo coronavírus de 2019 (COVID-19) é uma enfermidade de notificação compulsória causada por um novo coronavírus chamado do inglês de Severe Acute Respiratory Syndrome Coronavirus (SARS-CoV-2) que apresenta um espectro clínico variando de infecções assintomáticas a quadros graves. De acordo com a Organização Mundial da Saúde (OMS), a maioria das pessoas com a COVID-19 (cerca de 80\%) podem ser assintomáticos e em torno de $20 \%$ dos casos estimados podem necessitar de suporte hospitalar em decorrência de sintomatologia respiratória. Destes casos aproximadamente 5\% ainda podem carecer de suporte ventilatório em virtude da insuficiência respiratória (Harapan et al., 2020).

A OMS em janeiro de 2020 ponderou o surto do novo coronavírus como uma Emergência de Saúde Pública de Importância Internacional (ESPII)- considerada como o mais alto nível de alerta previsto no Regulamento Sanitário Internacional e, em março de 2020 classificou o evento em nível pandêmico (Who, 2020).

A pandemia da COVID-19 tem provocado múltiplas reflexões sob o contexto social no tocante as desigualdades sociais e os sistemas de saúde até então não muito compreendidas pelas sociedades em geral. As múltiplas formas de transmissão do SARS-CoV-2 permite disseminação de forma acelerada, e ainda, até o momento sem tratamento específico e tampouco medidas de imunização, impõe a todos, situações de exposição, vulnerabilidades e risco (Barbosa, 2020).

Alguns países com sistemas de saúde fragilizados, e com políticas públicas que pouco correspondem às reais vulnerabilidades comunitárias, sem colocar em pauta as iniquidades sociais, alteraram suas realidades e foram obrigados a conviver com uma realidade de morbimortalidade anteriormente não esperada. Nesta perspectiva os componentes notoriamente delimitados, sem logística operacional efetiva e sustentável, forçaram os gestores ao redor do mundo agir de maneira oportuna preconizando medidas eficazes em seus respectivos sistemas de saúde para a contenção e rastreamento do avanço viral (Barbosa, 2020).

No campo da saúde coletiva, a perspectiva de adoecer já caracteriza o indivíduo em situação de vulnerabilidade. A temática se agrava ao ponto que, pessoas por inúmeros fatores estão suscetíveis aos determinantes da relação saúde-doença. Neste contexto, é necessário dar ênfase às necessidades desta parcela da população de modo que não sejam ofertados apenas os cuidados técnicos, mas a possibilidade de promover mudanças no contexto social (Carvalho et al., 2020).

Somado a esses dados já preocupantes na população geral, está o desafio do combate da COVID-19 e as subpopulações vulneráveis, como moradores em situação de rua, moradores de favelas, pacientes com tuberculose, pessoas que vivem com o HIV, idosos, indígenas e pessoas em privação de liberdade. Estima-se que pessoas com comorbidades, em situações de vulnerabilidade social e risco tendem a desenvolver formas mais graves da doença (Carvalho et al., 2020). 
A OMS preconizou ações sociais e sanitárias para combater o avanço do SARS-CoV-2 em escala mundial, utilizando de estratégias comunitárias e uso de tecnologias em saúde para acompanhamento da disseminação da doença e do número de infectados. Estas tecnologias quando associadas a fontes de informações contribuem para a caracterização dos locais mais vulneráveis. Tais ferramentas, são fundamentais para realização de campanhas de saúde para o controle e prevenção da COVID-19. Essa organização tem sido enfática quanto à ampliação da transmissibilidade do vírus em áreas ou territórios marcados por seus altos índices de desigualdade social e pobreza, como a exemplo as periferias e favelas (Who, 2020).

As favelas e periferias constituem-se como territórios de moradias com habitações com alta densidade populacional (quantidade de pessoas na mesma área), condições precárias a despeito das condições de alimentação, infraestrutura urbana e sanitária e, não obstante a violência urbana que assolam estes nichos (Who, 2020).

É fato, que as condições insalubres, de grande densidade populacional e áreas subnormais, como favelas são nichos importantes para a propagação do vírus, que ao avançar nessas áreas encontram um perfil populacional com outras doenças como a tuberculose, HIV, diabetes, hipertensão, encontro esse que pode deflagrar situação dramática e crise humanitária nessas regiões (Carvalho et al., 2020).

Desse modo, torna-se relevante investigar como a COVID-19 tem impactado no acesso da população que vivem num contexto social, de saúde e econômico, em especial aquelas mais vulneráveis como pessoas morando em favelas. Frente ao exposto o objetivo desta revisão foi identificar as evidências na literatura acerca dos impactos e desafios que a COVID-19 têm causado nas favelas.

\section{Metodologia}

O presente estudo consiste em uma revisão da literatura realizada no período de julho de 2020 a agosto de 2020 conforme as seguintes etapas: 1) identificação do tema e seleção da hipótese ou questão de pesquisa; 2) estabelecimento de critérios para inclusão e exclusão de estudos; 3) definição das informações a serem extraídas dos estudos selecionados/categorização dos estudos; 4) leitura e avaliação dos estudos incluídos; 5) interpretação dos resultados; e 6) síntese dos achados e redação do relatório científico (Souza et al., 2010).

Na revisão integrativa, utiliza-se de uma abordagem metodológica mais ampla referente aos demais tipos de revisões, permitindo a inclusão dos estudos experimentais e não-experimentais para uma percepção completa do fenômeno analisado. Concilia também dados da literatura teórica e empírica, além da incorporação de um enorme leque de propósitos: definição de conceitos, revisão de teorias e evidências, e análise de problemas metodológicos de um tópico particular. A vasta amostra, agrupada à multiplicidade de propostas, deve gerar um panorama consistente e compreensível de conceitos complexos, teorias ou problemas de saúde relevantes para a enfermagem (Mendes et al., 2008).

O problema de pesquisa foi elaborado por meio da estratégia PICO (paciente, intervenção, comparação e resultados), onde: $\mathrm{P}$ = Moradores de favelas; $\mathrm{I}$ = Impactos do COVID-19; C = Os impactos causados pelo COVID-19 nas favelas; $\mathrm{O}=$ Desafios enfrentados pelos moradores das favelas.

Para a identificação dos artigos do tema em questão, realizou-se uma busca nas bases de dados: Portal de Periódicos da Coordenação de Aperfeiçoamento de Pessoal de Nível Superior do Ministério da Educação (CAPES/MEC), no Scientific Electronic Library Online (SciELO) e Pubmed. Utilizou-se os descritores e suas combinações nos idiomas português e inglês: "Slums" and "Covid-19"; "Favelas" and "covid-19". Os critérios de inclusão definidos para a seleção dos artigos foram: artigos publicados em português e inglês; disponíveis na íntegra que retratassem a temática referente aos impactos e desafios nas favelas pelo COVID-19, publicados em 2020. As publicações duplicadas e que não estavam alinhadas aos critérios de inclusão foram excluídas, assim como estudos com animais, artigos de revisão e notas técnicas. 
As etapas de seleção foram organizadas da seguinte maneira: Etapa 1 - busca com o uso dos descritores e ano de publicação de 2020; Etapa 2- aplicabilidade dos critérios de inclusão; Etapa 3 - leitura de títulos e resumos realizada por três dos autores; Etapa 4 - leitura do artigo na íntegra, a partir desta última, tem-se os resultados. Tais etapas encontram-se na Figura 1 .

Figura 1 - Fluxograma de seleção e identificação dos estudos seguindo as recomendações PICO.

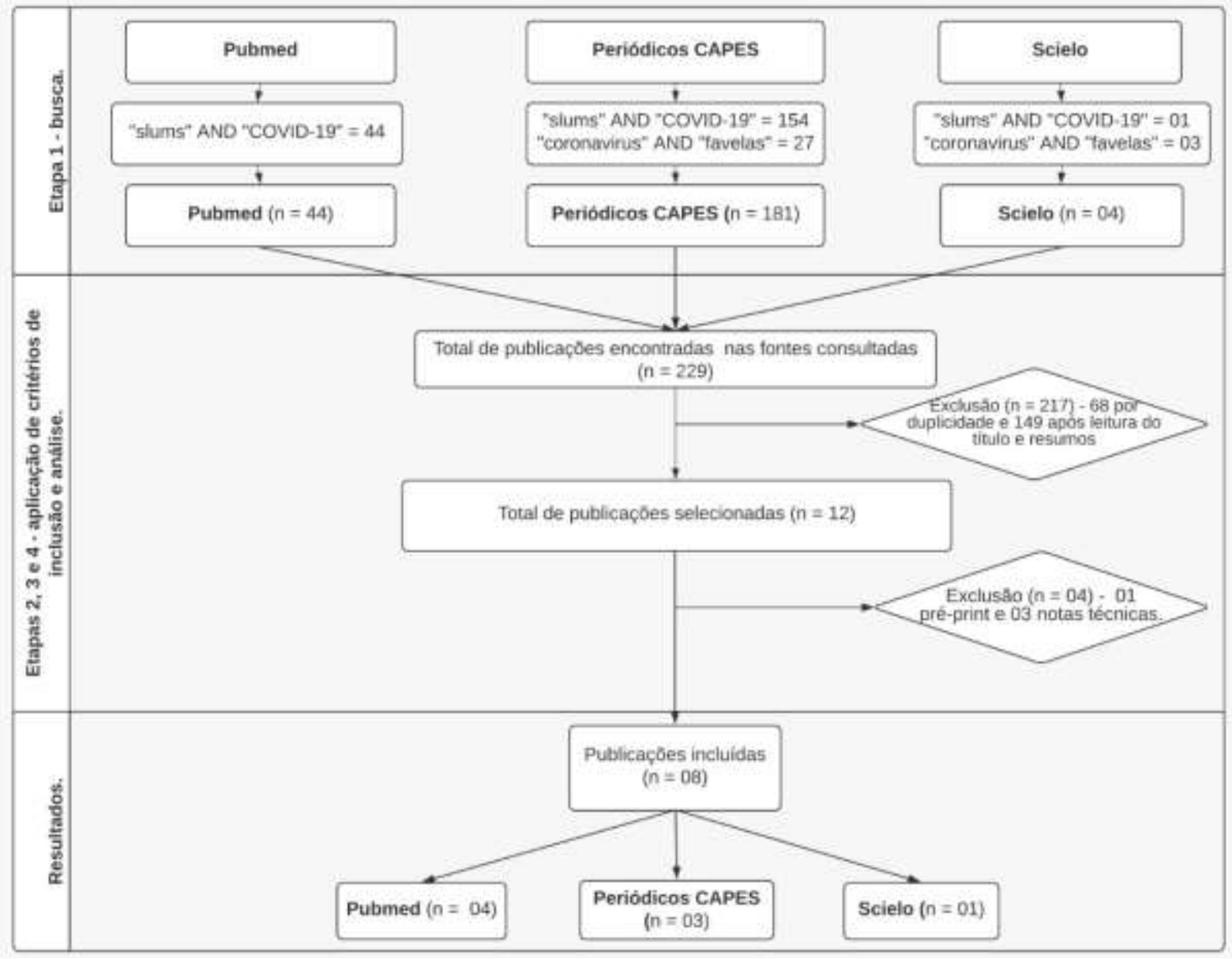

Fonte: Dados da pesquisa.

\section{Resultados}

De acordo com os critérios de inclusão estabelecidos, foram selecionados 8 artigos, sendo 5 (62,5\%) de literatura estrangeira e $3(37,5 \%)$ produzidos no Brasil.

Em síntese, após a leitura dos artigos e extração dos dados, os estudos selecionados evidenciaram os impactos sobre as condições de vulnerabilidade social que a pandemia de COVID-19 tem propiciado, principalmente nos eixos: economia, serviços de saúde, habitação, alimentação, e medidas de higiene e proteção.

No que tange ao contexto internacional, ficou evidente as disparidades encontradas em diferentes contextos e países, como por exemplo: as questões de acesso aos serviços de saúde que ficaram fragilizadas em Bangladesh, Quênia, Nigéria e Paquistão que, anteriormente à pandemia de COVID-19, foi relatado que as pessoas recorriam mais aos serviços de saúde para consultas de promoção, prevenção e reabilitação. Tal fato é alarmante, uma vez que, nesses países existem outras epidemias ainda não erradicadas e/ou controladas que assolam as realidades dessas populações e acabaram por se agravar com a chegada da COVID-19, ocasionando a falta de adesão nos tratamentos de diversas outras patologias (Ahmed et al., 2020). 
O estudo realizado por Corbum et al. (2020), relata que os assentamentos informais (favelas) do Sul global estão menos preparados para a pandemia de COVID-19, por geralmente se tratar dos países em subdesenvolvimento no mundo, ainda nesse sentido, o autor relata as principais fragilidades desses assentamentos, que carecem de recursos básicos como: água, saneamento básico, coleta de lixo, hiper população e dificuldades em cumprir a quarentena de maneira adequada, retratando assim as vulnerabilidades em suas diferentes esferas para as populações que residem nas favelas. Já na Índia, foi demonstrado que as ações recomendadas pela OMS são impraticáveis pelos motivos supracitados (Patel, 2020).

Num contexto nacional, ficou evidente que o Brasil ainda carece de diversos recursos para conseguir combater o COVID-19, especialmente nos locais como as favelas que tem indicadores de maior vulnerabilidade que os demais locais, afetando a população desses nichos com questões quanto a economia, a alimentação, medidas de prevenção, violência e especialmente a falta de recursos e políticas públicas de saúde (Oliveira, 2020; Mendonça et al., 2020; Pereira et al., 2020; Shammi et al., 2020).

No Quadro 1 observa-se a síntese dos artigos selecionados para o estudo, apresentados por ordem alfabética dos autores.

Quadro 1 - Características dos estudos incluídos na revisão integrativa sobre o impacto da pandemia de COVID-19 nas favelas de acordo com o ano, primeiro autor, país, objetivo e principais resultados, 2020.

\begin{tabular}{|c|c|c|c|c|}
\hline Ano & Autor & País & Objetivo & Principais Resultados \\
\hline 2020 & $\begin{array}{l}\text { Ahmed et } \\
\quad \text { al. }\end{array}$ & Bangladesh & $\begin{array}{l}\text { Comparar o acesso a } \\
\text { cuidados de saúde antes e } \\
\text { durante COVID-19 com } \\
\text { quem trabalha e vive em } \\
\text { favelas e comunidades } \\
\text { periféricas. }\end{array}$ & $\begin{array}{l}\text { Entre março de } 2018 \text { e maio de } 2020 \text {, foram entrevistados } 860 \text { líderes } \\
\text { comunitários, residentes, trabalhadores e autoridades locais. Antes do } \\
\text { COVID-19 as pessoas relataram frequentar vários serviços de } \\
\text { prevenção, diagnóstico e tratamento } \\
\text { Com a chegada da COVID-19 houve uma redução no acesso aos } \\
\text { cuidados de saúde, incluindo os preventivos. Houve dificuldades de } \\
\text { acessar aos serviços de saúde e medo de se infectar com a COVID-19, } \\
\text { além de ter ocorrido aumento nos custos de serviços de saúde } \\
\text { enquanto a renda da população diminuía por causa da pandemia. }\end{array}$ \\
\hline 2020 & Andrade & Brasil & $\begin{array}{l}\text { Investigar o que as } \\
\text { populações das favelas } \\
\text { brasileiras têm feito para } \\
\text { combater o COVID-19. }\end{array}$ & $\begin{array}{l}\text { Como resultado, o movimento de pessoas nas ruas das favelas } \\
\text { continua alto, à medida que as pessoas continuam a trabalhar. Em } \\
\text { Paraisópolis, ao contrário do resto de São Paulo fechada, a maioria } \\
\text { dos bares e lojas permanecem abertos porque as pessoas precisam } \\
\text { ganhar dinheiro para despesas básicas de subsistência. } \\
\text { Dado o aumento exponencial dos casos positivos de COVID-19, os } \\
\text { Grupos das favelas (G10) negociaram com a secretaria do estado de } \\
\text { São Paulo a criação de dois hospitais de campanha em duas escolas } \\
\text { públicas que já estavam fechadas em decorrência da pandemia de } \\
\text { COVID-19. }\end{array}$ \\
\hline 2020 & $\begin{array}{c}\text { Corburn et } \\
\text { al. }\end{array}$ & $\begin{array}{l}\text { Estados } \\
\text { Unidos da } \\
\text { América }\end{array}$ & $\begin{array}{l}\text { Estabelecer as políticas } \\
\text { que ajudarão as } \\
\text { comunidades de favelas } \\
\text { no mundo a lidarem com } \\
\text { COVID-19. }\end{array}$ & $\begin{array}{l}\text { Esse artigo observa as vulnerabilidades das pessoas nesses } \\
\text { assentamentos informais e argumenta que qualquer programa de } \\
\text { assistência deve reconhecer estas realidades para que as políticas } \\
\text { governamentais não prejudiquem ainda mais a sobrevivência de } \\
\text { grandes segmentos da população dessas comunidades. } \\
\text { Os assentamentos informais do Sul global são os menos preparados } \\
\text { para a pandemia de COVID-19, o artigo descreve que o preço que } \\
\text { isso custará em vidas e meios de subsistência terá efeitos imediatos e } \\
\text { duradouros. Ao passo que a resposta precisará envolver diversos } \\
\text { atores, como: governos nacionais e locais, agências internacionais } \\
\text { bilaterais e multilaterais, fundações e Organizações Não } \\
\text { Governamentais (ONG). Além de ser necessário dispor de educação } \\
\text { continuada e treinamento para a comunidade enfrentar a doença a } \\
\text { longo prazo. }\end{array}$ \\
\hline 2020 & $\begin{array}{l}\text { Mendonça } \\
\text { et al. }\end{array}$ & Brasil & $\begin{array}{l}\text { Abordar a questão social } \\
\text { das desigualdades } \\
\text { socioeconômicas no } \\
\text { Brasil e seu impacto na } \\
\text { organização das políticas } \\
\text { públicas nas grandes } \\
\text { cidades que interferem na }\end{array}$ & $\begin{array}{l}\text { Foca nas iniciativas surgidas no âmbito da sociedade e Estado } \\
\text { valorizando a solidariedade social, a democracia participativa e as } \\
\text { iniciativas comunitárias. Por fim, aponta as lições que a pandemia } \\
\text { trouxe para o campo da Atenção Primária em Saúde e da Saúde } \\
\text { Coletiva. } \\
\text { Emergiram iniciativas como: durante a pandemia, dar ênfase no } \\
\text { cuidado das populações em situação de vulnerabilidade, tornar as ruas }\end{array}$ \\
\hline
\end{tabular}




\begin{tabular}{|c|c|c|c|c|}
\hline & & & $\begin{array}{l}\text { atuação da Atenção } \\
\text { Primária à Saúde (APS) } \\
\text { no enfrentamento da } \\
\text { COVID-19. }\end{array}$ & $\begin{array}{l}\text { menos nociva para quem nela permanecer em consequência da } \\
\text { desigualdade socioeconômica brasileira; e dentre as lições que a } \\
\text { pandemia trouxe, destaca-se a preocupação em não isolar a favela da } \\
\text { cidade. }\end{array}$ \\
\hline 2020 & $\begin{array}{l}\text { Nascimento } \\
\quad \text { et al. }\end{array}$ & Brasil & $\begin{array}{l}\text { Relatar os principais } \\
\text { desafios quanto a } \\
\text { transmissão do COVID- } \\
19 \text { nas favelas do Brasil. }\end{array}$ & $\begin{array}{l}\text { As peculiaridades das populações que vivem em regiões subnormais } \\
\text { as aglomerações surgem como um grande desafio para a saúde } \\
\text { pública, principalmente diante de uma pandemia, que pode se } \\
\text { espalhar para essas comunidades, com consequências irreversíveis } \\
\text { para todo o país, incluindo os habitantes de regiões urbanizadas. } \\
\text { Quanto aos desafios, os autores relatam que os aglomerados } \\
\text { subnormais possuem alta densidade demográfica e neste sentido } \\
\text { relatam que é inevitável a aglomeração de pessoas em situação de } \\
\text { vulnerabilidade socioeconômica, com baixo grau de escolarização, } \\
\text { condições precárias de saneamento básico e menores proporções no } \\
\text { acesso aos serviços de saúde. }\end{array}$ \\
\hline 2020 & $\begin{array}{c}\text { Santos et } \\
\text { al. }\end{array}$ & Brasil & $\begin{array}{l}\text { Evidenciar áreas de maior } \\
\text { vulnerabilidade aos casos } \\
\text { graves da doença na } \\
\text { cidade do Rio de Janeiro, } \\
\text { Brasil, caracterizada por } \\
\text { grande heterogeneidade } \\
\text { socioespacial. }\end{array}$ & $\begin{array}{l}\text { A espacialização do índice de vulnerabilidade aos casos graves na } \\
\text { cidade do Rio de Janeiro evidencia a existência de áreas mais } \\
\text { vulneráveis em diferentes porções do território, refletindo a sua } \\
\text { complexidade urbana. Contudo, é possível observar que as áreas de } \\
\text { maior vulnerabilidade pela falta de recursos socioeconômicos estão } \\
\text { nas regiões Norte e Oeste da cidade e em comunidades carentes } \\
\text { encrustadas nas áreas nobres como as zonas Sul e Oeste. }\end{array}$ \\
\hline 2020 & $\begin{array}{c}\text { Shammi et } \\
\text { al. }\end{array}$ & Bangladesh & $\begin{array}{l}\text { Compreender a percepção } \\
\text { pública da r crise } \\
\text { socioeconômica e do } \\
\text { estresse humano em } \\
\text { locais com recursos } \\
\text { limitados em Bangladesh } \\
\text { durante o surto de } \\
\text { COVID-19. }\end{array}$ & $\begin{array}{l}\text { A COVID-19 criou ainda mais desemprego, privação, fome e } \\
\text { conflitos sociais. A governança fraca no frágil sistema de saúde } \\
\text { agrava a ansiedade do público em geral, visto que as instalações de } \\
\text { teste do COVID-19 estão centradas nas áreas urbanas, local em que } \\
\text { inúmeros indivíduos a serem testados. Além disso, há um mínimo ou } \\
\text { nenhum tratamento hospitalar dedicados para pacientes com COVID- } \\
\text { 19. Essas são as principais dificuldades encontradas, juntamente com } \\
\text { a interrupção de outros serviços de saúde. }\end{array}$ \\
\hline 2020 & Patel & Índia & $\begin{array}{l}\text { Avaliar a eficácia e as } \\
\text { implicações } \\
\text { distanciamento social, } \\
\text { lavagem frequente das } \\
\text { mãos e bloqueio no } \\
\text { contexto de favelas em } \\
\text { cidades indianas, onde a } \\
\text { superlotação e a falta de } \\
\text { acesso a água e } \\
\text { saneamento, } \\
\text { dependência de salários } \\
\text { diários para sustento e } \\
\text { subsistência são comuns. }\end{array}$ & $\begin{array}{l}\text { Por meio do uso de várias fontes de dados, é demonstrado que não } \\
\text { apenas essas medidas (OMS) serão difíceis de alcançar em favelas em } \\
\text { curto prazo devido às características específicas desses habitats, mas } \\
\text { que terão novos desafios a longo prazo devido aos impactos } \\
\text { desproporcionais sobre os pobres urbanos. } \\
\text { Dentre os desafios listados pelo autor, destaca-se o de examinar como } \\
\text { as medidas de prevenção da Organização Mundial da Saúde afetarão } \\
\text { as populações marginalizadas no contexto das realidades únicas da } \\
\text { Índia urbana em geral e das favelas em particular. }\end{array}$ \\
\hline
\end{tabular}

Fonte: Dados da pesquisa.

\section{Discussão}

Num contexto geral, a OMS preconizou ações de prevenção e combate ao novo coronavírus em nível mundial, todavia, é necessário levar em consideração as particularidades de cada local, para que assim as ações se tornem realmente efetivas nestes aspectos, uma vez que a pandemia é vivida e sentida de maneiras diferentes pelas distintas populações em suas respectivas realidades e locais (Who, 2020).

Vale ressalvar que as problemáticas encontradas pelos autores em âmbito internacional e nacional foram similares num contexto geral, sobretudo, emergiram questões de cunho social e das políticas públicas de saúde, como por exemplo: situações de carência de recursos, superlotação nas favelas, déficits econômicos, violência e condições precárias para moradia e atividades de prevenção (Ahmed et al., 2020; Santos et al., 2020; Shammi et al., 2020).

Para retardar o crescente número dos casos positivos de COVID-19, um bloqueio internacional foi imposto em várias fases, tendo pautado suas decisões em sua maioria nas recomendações da OMS. No Brasil, foi implementado um sistema no qual os territórios foram subdivididos, e sendo classificados em diferentes fases com base na incidência e prevalência da doença (Mendonça et al., 2020). 
Se por um lado o isolamento social tinha o propósito de garantir a redução dos casos positivos de COVID-19, por outro, os efeitos adversos evidenciaram o profundo despreparo das comunidades para tal situação, gerando déficits financeiros, sentimentos emergidos de medo/impotência, acometimentos na saúde mental e até mesmo fragilizando determinadas subpopulações em diversos nichos geográficos, a exemplo: os moradores de favelas e de periferias (Mendonça et al., 2020).

De acordo com o levantamento da Organização das Nações Unidas, aproximadamente 1,6 milhões de pessoas fixam suas residências em bairros informais ora sem infraestrutura, ora sem saneamento básico, e por vezes, sem ambos, além da escassez dos recursos de moradia como por exemplo: água tratada e eletricidade, e consequentemente acabam por ter os acessos aos serviços públicos de saúde fragilizados (ONU, 2020).

Segundo o levantamento realizado pelo Instituto Brasileiro de Geografia e Estatística (IBGE, 2018), no Brasil existem cerca de 13.151 aglomeramentos subnormais (favelas). De forma geral, as favelas são espaços urbanos com dinâmicas socioespaciais distintas dos demais nichos geográficos, que não estão sendo levados em consideração na formulação das estratégias de enfrentamento pelas agências internacionais/nacionais de saúde.

Em abril de 2020 a epidemia de COVID-19 já havia atingido todos os estados brasileiros, incluindo os territórios rurais e remotos, e ao ponto que a epidemia se alastra pelos estados e cidades do país, das áreas nobres às favelas, acaba por evidenciar a dura realidade das desigualdades nas esferas sociais e da saúde (Floss et al., 2020).

Os autores discutem que diversas pessoas vivem em condições questionáveis, e neste sentido, destaca-se os espaços limitados, nos quais é notado um amontoado de pessoas/famílias em grandes proporções, ou seja, estes moradores residem na cidade, porém não gozam de certos privilégios, uma vez que vivem em amontoados desurbanizados, desprovidos ainda de acesso às condições como saneamento básico, moradia adequada e serviços de saúde precários (Oliveira, 2020; Ahmed et al., 2020; Pereira et al., 2020).

A pandemia de COVID-19 acabou por eviscerar as iniquidades sociais que assolam a humanidade de uma maneira mais ostensiva, fazendo com que essas populações no mundo a fora vivenciassem a quarentena de uma maneira mais excruciante (Patel, 2020; Santos et al., 2020; Shammi et al., 2020).

Para além dessas colocações, vale ressalvar que a OMS têm sido enfática nas suas recomendações sobre as medidas de proteção contra a COVID-19 para toda a população mundial, mas por outro lado, poderão ser eficazes estas recomendações para este tipo de população que se encontra em situação de vulnerabilidade social? (Who, 2020).

Neste contexto, vão emergindo diversas problemáticas ressalvadas pelos estudos encontrados, questões como: Poderão estes moradores de favelas lavar as mãos com frequência quando a limitada água que é disponível ainda tem que ser racionada para o consumo e preparo dos alimentos? Conseguirão manter o distanciamento social preconizado em locais concentrados de habitação, nos quais a privacidade é quase impossível? (Macedo, 2020).

Ainda neste sentido, diversos desses aglomerados no Brasil, ainda se deparam com o policiamento civil e até mesmo o das forças militares em alguns casos, no fundamento de combate/enfrentamento ao crime, logo, a quarentena para estas populações emergem condições que acabam por agravar tal processo (Pereira et al., 2020).

Não obstante, a pandemia de COVID-19, acaba por ambientar-se a diversas outras emergências sanitárias e/ou sociais para os moradores de favelas e periferias no mundo, neste sentido temos a emergência alimentar, a qual podemos categorizar a fome como um marcador social, que permeia em diversos locais e ainda acabam por ceifar diversas vidas anualmente (Fao, 2019).

Em um levantamento realizado pela Organização das Nações Unidas para Alimentação e Agricultura relatou que embora seja muito cedo para dispor de evidências sobre o impacto da COVID-19 no estado nutricional das populações, estimase que a pandemia eleve os níveis de desnutrição em todas as suas formas e principalmente nas famílias/populações vulneráveis, e isto pode ocorrer devido a seis principais fatores, são eles: o aumento da insegurança alimentar; o esmagamento 
das capacidades dos sistemas de saúde para fornecer serviços curativos e preventivos, incluindo cuidados infantis e pré-natais; o possível aumento na morbidade de bebês e crianças pequenas; a descontinuação ou suspensão das atividades de nível comunitário; o fechamento das escolas; a deterioração das práticas de cuidado infantil e por fim os padrões de compras alterados (Fao, 2019).

Outrora, o fechamento das escolas, acabam por aglomerar as crianças nas ruas, acabando por propiciar maiores chances de infecção comunitária nas favelas por meio das crianças. O que já é relatado em literatura num estudo realizado por Heald-Sargent et al. (2020), que verificou ao reunir amostras retiradas do nariz de 145 pacientes com COVID-19, confirmadas por PCR, os grupos do estudo foram subdivididos em três: crianças com até cinco anos de idade (46 pacientes); crianças com cinco a 17 anos de idade (51 pacientes); e adultos com 18 a 65 anos (48 pacientes), onde ficou evidente que as crianças apresentaram cargas virais em maiores quantidades que os adultos.

E ainda nesta perspectiva, emergem situações como a falta de merenda escolar que para muitas crianças é a principal refeição do dia, porém, afim de mudar este cenário no estado de São Paulo, no Brasil, foi implementado o programa de merenda em casa para crianças e famílias que se enquadraram dentro dos critérios de seleção da normativa (São Paulo, 2020), o que acabou por minimizar os impactos da fome, no entanto, estas ações não são realizadas em âmbito nacional, o que impacta de forma negativa a vida das outras crianças das demais periferias.

E não menos importante, o aglomeramento das pessoas em favelas e periferias fizeram emergir questões sobre a violência doméstica, algumas evidências indicam que ao redor do mundo, uma em cada três mulheres sofrem violência domiciliar, e ainda relatam que comumente esta violência é praticada pelo parceiro íntimo, e que 1/3 dos feminicídios sejam cometidos pelos parceiros íntimos (Bradbury \& Isham, 2020).

Em crises anteriores nos outros países, já era demonstrado que a violência doméstica aumenta exponencialmente durante e após o período de crises humanitárias, desastres de proporções vastas e epidemias. Lamentavelmente os períodos de quarentena inclinam-se por colocar mulheres que vivem em relacionamentos abusivos perante maior risco e, consequentemente, ocorre um crescimento do padrão de violência doméstica de maneira recorrente por todo o mundo. Alguns dos estudos, apontam o Brasil com dados inquietantes, nos quais ocorrem um aumento de cerca de 40 a $50 \%$ dos casos de violência doméstica (Bradbury \& Isham, 2020).

Portanto, fica evidente o quão é necessário o fortalecimento das Políticas Públicas de Atenção à Saúde das populações em situação de vulnerabilidade, melhores condições ao acesso à saúde, e melhores condições humanitárias, visto que em sua maioria, estes são os locais mais frágeis, além de serem afetados em proporções mais árduas perante as crises sanitárias que açoitam a humanidade, como a de COVID-19 (Floss et al., 2020).

A literatura internacional e nacional sobre os moradores das periferias e favelas num contexto da pandemia de COVID-19 ainda é muito escassa, especialmente no âmbito de produção nacional, carecendo de maiores estudos para estas populações.

\section{Conclusão}

As comunidades periféricas apresentam desafios para o enfrentamento da COVID-19. A partir dos estudos analisados, emergiram inúmeros desafios, dentre eles: os marcadores sociais da diferença, os nichos demográficos que por si só geram aglomerações, o que vai contra as recomendações da OMS, as dificuldades no acesso aos meios de saúde, a escassez de renda para as despesas básicas.

Dentre os devastadores impactos que abalroaram estas populações, nota-se que os indicadores sociais e biomédicos vão na contramão do preconizado, gerando um aumento drástico da infecção de COVID-19 por meio comunitário, óbitos, perdas de empregos, e condições insalubres para o cumprimento adequado da quarentena. Diante do exposto, sugerimos que 
outros trabalhos sejam realizados utilizando a mesma população e temática de estudo sob outras circunstâncias que a pandemia de COVID-19 tem causado.

\section{Referências}

Ahmed, S. A. S., Ajisola, M., Azeem, K., Bakibinga, P., Chen, Y. F., Choudhury, N. N., \& Yusuf, R. (2020). Impact of the societal response to COVID-19 on access to healthcare for non-COVID-19 health issues in slum communities of Bangladesh, Kenya, Nigeria and Pakistan: results of pre-COVID and COVID-19 lockdown stakeholder engagements. BMJ Global Health, 5(8), e003042.

Boliko, M. C. (2019). FAO and the situation of food security and nutrition in the world. Journal of nutritional science and vitaminology, 65, S4-S8.

Bradbury-Jones, C., \& Isham, L. (2020). The pandemic paradox: The consequences of COVID-19 on domestic violence. Journal of clinical nursing.

Corburn, J., Vlahov, D., Mberu, B., Riley, L., Caiaffa, W. T., Rashid, S. F., \& Ayad, H. (2020). Slum health: arresting COVID-19 and improving well-being in urban informal settlements. Journal of urban health, 97(3), 348-357.

de Mendonça, M. H. M., da Silva Junior, A. G., Cunha, C. L. F., \& Latgé, P. K. (2020). A pandemia COVID-19 no Brasil: ecos e reflexos nas comunidades periféricas. APS em Revista, 2(2), 162-168.

de Oliveira Andrade, R. (2020). The Brazilian slums hiring their own doctors to fight covid-19. Bmj, 369.

Floss, M., Franco, C. M., Malvezzi, C., Silva, K. V., Costa, B. D. R., Silva, V. X. D. L., \& Duarte, D. R. (2020). A pandemia de COVID-19 em territórios rurais e remotos: perspectiva de médicas e médicos de família e comunidade sobre a atenção primária à saúde. Cadernos de Saúde Pública, 36.

Heald-Sargent, T., Muller, W. J., Zheng, X., Rippe, J., Patel, A. B., \& Kociolek, L. K. (2020). Age-related differences in nasopharyngeal severe acute respiratory syndrome coronavirus 2 (SARS-CoV-2) levels in patients with mild to moderate coronavirus disease 2019 (COVID-19). JAMA pediatrics, 174(9), 902-903.

IBGE. Instituto Brasileiro de Geografia e Estatística. Estimativas da população residente com data de referência de $1^{\circ}$ de julho de 2018.

Macedo, Y. M., Ornellas, J. L., \& do Bomfim, H. F. (2020). COVID-19 nas favelas e periferias brasileiras. Boletim de Conjuntura (BOCA), 2 (4), 50-54.

Mendes, K. D. S., Silveira, R. C. D. C. P., \& Galvão, C. M. (2008). Revisão integrativa: método de pesquisa para a incorporação de evidências na saúde e na enfermagem. Texto \& contexto-enfermagem, 17, 758-764.

ONU. Organizações das Nações Unidas Habitat. 2020. https://nacoesunidas.org/agencia/onuhabitat/.

Patel, A. (2020). Preventing COVID-19 Amid Public Health and Urban Planning Failures in Slums of Indian Cities. World Medical \& Health Policy, 12(3), $266-273$.

Pereira, R. J., do Nascimento, G. N. L., Gratão, L. H. A., \& Pimenta, R. S. (2020). The risk of COVID-19 transmission in favelas and slums in Brazil. Public health, 183, 42 .

Pinho, S. B. (2020). A Atenção Primária a Saúde no contexto da COVID19. HU Revista, 46, 1-2.

Pinto, L. F., \& Rocha, C. M. F. (2016). Inovações na Atenção Primária em Saúde: o uso de ferramentas de tecnologia de comunicação e informação para apoio à gestão local. Ciência \& Saúde Coletiva, 21, 1433-1448.

Pires, L. N., Carvalho, L., \& XAVIER, L. D. L. (2020). COVID-19 e desigualdade: a distribuição dos fatores de risco no Brasil. Experiment Findings, 21.

Santos, J. P. C. D., Siqueira, A. S. P., Praça, H. L. F., \& Albuquerque, H. G. (2020). Vulnerabilidade a formas graves de COVID-19: uma análise intramunicipal na cidade do Rio de Janeiro, Brasil. Cadernos de Saúde Pública, 36, e00075720.

São Paulo. Merenda em Casa. (2020). https://merendaemcasa.educacao.sp.gov.br/.

Shammi, M., Bodrud-Doza, M., Islam, A. R. M. T., \& Rahman, M. M. (2020). COVID-19 pandemic, socioeconomic crisis and human stress in resourcelimited settings: a case from Bangladesh. Heliyon, 6(5), e04063.

Souza, M. D., Silva, M. D., Carvalho, R. D., Souza, M. D., Silva, M. D., \& Carvalho, R. D. (2010). Revisão integrativa: o que é e como fazer. Einstein (São Paulo), 8 (1), 102-106. 